\title{
Review
}

\section{Reviews of Research on Risk Factors of Hepatitis C Virus Infection}

\author{
Chao Meng, Na Li, Zhaoxiao Tong, Huangxin Yan, Shenxiao Min \\ Clinical Laboratory, The Tianjin Second People's Hospital, Tianjin, China
}

\author{
Keywords \\ Hepatitis C virus; Risk factors; Unsafe medical \\ injections; Injection drug use; High-risk sexual \\ behavior
}

\section{Correspondence}

Shenxiao Min,

E-mail: henxiaomin420@163.com

DOI: 10.1515/ii-2017-0097

\begin{abstract}
Viral hepatitis $\mathrm{C}$ is one of the most prevalent infectious diseases in the world and may cause serious hepatic diseases in the future. Hepatitis C-infected people account for approximately $2 \%$ to $3 \%$ of the world's population. The main causes of hepatitis $\mathrm{C}$ infection in developing countries are unsafe medical injection and contaminated blood and blood products; whereas in developed countries, it is mainly caused by injection, drug abuse, and high-risk sexual behavior. The focus of hepatitis $\mathrm{C}$ prevention and control should be placed on safer blood supply, safer health care and related unnecessary injection, reduction of injection drug use, and high-risk sexual behavior because effective vaccine and postexposure prophylaxis are not yet available.
\end{abstract}

Viral hepatitis $\mathrm{C}$ (hepatitis $\mathrm{C}$ ) is one of the most frequent incidences of infectious diseases caused by hepatitis $\mathrm{C}$ virus (HCV) infection. Approximately $2 \%$ to $3 \%$ of the world' s population is infected by HCV. Hepatitis $\mathrm{C}$ infection is featured by liver damage, in which most of the people are generally susceptible but no effective vaccine and postexposure prevention exist thus far. $\mathrm{HCV}$ is often considered a "silent killer" because the patients have no symptoms or no specific symptoms after being infected, and many people are unaware of their own infection until the occurrence of cirrhosis or hepatocellular carcinoma ${ }^{[1,2]}$. Moreover, the spontaneous clearance of patients with HCV is weak; therefore, approximately $70 \%$ of patients will suffer from chronic liver diseases. Developed countries rank the highest in end-stage liver disease, and hepatitis C-related death rate in the United States has increased significantly more than HIVrelated death rate ${ }^{[1-3]}$. In recent years, an epidemic outbreak of hepatitis $\mathrm{C}$ in many cities and aggregation epidemic in some rural areas have caused public attention and social panic $^{[4]}$. The prevention and control of the disease depend on accurate and reliable epidemiological data, particularly the etiologic research on infection. This paper summarizes the risk factors of hepatitis $\mathrm{C}$ infection and provides an objective reference for the on-site epidemiological investigation, the modification of diagnostic criteria of viral hepatitis $C$, and the formulation of prevention and control measures.

\section{latrogenic infection}

Blood transfusion or blood products, unsafe medical treatment, dialysis and surgical operation, and other iatrogenic infections are the most common causes for the outbreak of hepatitis $\mathrm{C}$ across the world. In some countries and regions, the rate of incidence and infection of hepatitis $\mathrm{C}$ declines after relevant prevention and control measures are applied. In some less developed countries, the spread of hepatitis $\mathrm{C}$ is caused by lack of disposable syringes and health care facilities and by re-use of needles, syringes, and infusion bags, among others ${ }^{[5]}$. Before the HCV was discovered and biological tests emerged, hepatitis $\mathrm{C}$ infection caused by blood transfusion, blood products, and blood donation is immeasurable. After measures of blood and blood products screening were implemented, the rate of incidence and infection of hepatitis $\mathrm{C}$ reduced, even lower than the general population in some areas ${ }^{[6]}$. In Egypt, intravenous therapy of anti-schistosomiasis is the main reason for the epidemic of hepatitis $\mathrm{C}$ infection causing serious iatrogenic infection. After the drugs of oral treatment of schistosomiasis are used and the norms of safe injection are set, the incidence of hepatitis $\mathrm{C}$ gradually decreased ${ }^{[7]}$. Injection of glass syringes increases the risk of hepatitis $\mathrm{C}$ infection, whereas the reduction of the use of glass syringes and of disposable syringes can effectively prevent hepatitis C. Guadagnino et al. found that the injection of glass syringe is one of the 
risk factors ( $\mathrm{OR}=3.2,95 \% \mathrm{CI}: 1.4-7.3)$; the rate of hepatitis $\mathrm{C}$ infection decreases from $12.6 \%$ to $5.7 \%$ after one-time syringe was used widely and that of all age groups decreases as well ${ }^{[8]}$. A certain relationship exists between the hepatitis $\mathrm{C}$ infection rate and injection frequency. The higher the injection frequency, the higher the probability of infection. Zhang et al. conducted a case-control study and found that 3 to 10 times of injection a year is a risk factor $(\mathrm{OR}=5.147$, 95\%CI: 1.601-16.550 $)^{[9]}$. Goyet et al. also concluded that compared with HIV single infection, HIV and HCV coinfected older people ( $>50$ years) (OR=5.4, 95\%CI: 1.5-19.6) five times more than intramuscular injection, and the risk factors are intravenous injection, blood transfusion $(\mathrm{OR}=3.4$, 95\%CI: 1.5-7.6), operation (OR=2.6, 95\%CI: 1.2-5.7), and colonoscopy $(\mathrm{OR}=2.4,95 \% \mathrm{CI}: 1.0-5.7)^{[10]}$. The incidence of dialysis is different in different areas; the incidence in developing countries is higher than that in developed countries. Su et al. found that the incidence in developing countries is five times that in developed countries ${ }^{[11]}$. Medical conditions may affect the incidence of disease; the incidence and prevalence of hepatitis $\mathrm{C}$ among dialysis patients have declined due to health prevention and isolation measures and gradual implementation of dialysis in most Western countries $^{[12]}$.

\section{Injection drug use}

With the emergence of new drugs, drug users have changed the manner of drug abuse. Injection drug use is still one of the most effective modes of spread of HCV infection. In developed countries, injection drug use has gradually become the main factor of hepatitis $\mathrm{C}$ infection. Although the proportion of hepatitis $\mathrm{C}$ infection caused by injection drug use in developing countries is lower than that in developed countries, the incidence of hepatitis $C$ is higher among injection drug users (IDU). Nelson et al. conducted a systematic review on IDU hepatitis $\mathrm{C}$ infection in 77 countries and found that IDU hepatitis $\mathrm{C}$ infection rate is over $80 \%$ in 12 countries, $60 \%$ to $80 \%$ in 25 countries, and $40 \%$ to $60 \%$ in 24 countries. Approximately 10 million IDUs worldwide are hepatitis $\mathrm{C}$ antibody-positive carriers; China, United States, and Russia are the three most infected countries, accounting for nearly half of the proportion ${ }^{[13]}$. Zhou et al. conducted a case-control study and found that hepatitis $\mathrm{C}$ infection is connected with the frequency of injection drug use $(1 / \mathrm{d})(\mathrm{OR}=1.69,95 \% \mathrm{CI}$ : $1.12-2.55)$, injection drug time ( $\geq 5$ years) $(\mathrm{OR}=2.26,95 \% \mathrm{CI}$ : 1.66-3.08), and shared syringe/needle (OR=2.63, 95\%CI:
1.85-3.75 ${ }^{[14]}$. Amin et al. conducted a cross-sectional study on IDU population and found that female drug addicts $(\mathrm{OR}=5.0,95 \% \mathrm{CI}: 2.0-10.0)$, unmarried drug users $(\mathrm{OR}=2.9$, $95 \% \mathrm{CI}: 1.9-4.4)$, drug use of 10 years above $(\mathrm{OR}=2.7,95 \% \mathrm{CI}$ : 1.8-3.9), and high frequency of injection ( $>1$ time / d) $(\mathrm{OR}=2.6,95 \% \mathrm{CI}: 1.6-4.2)$ are the risk factors for hepatitis $\mathrm{C}$ infection ${ }^{[15]}$.

Kassaian et al. also obtained a similar conclusion that hepatitis $\mathrm{C}$ infection is associated with high frequency of injection [OR=1.006, 95\%CI: 1.002-1.011, shared syringe/ needle (OR=4.19, 95\%CI: 2.22 to 7.9)]. Xia et al. conducted an analysis on drug users in China. Compared with noninjection drug users, injection drug use is the risk factor (OR=9.24, 95\% CI: 7.03-12.14); non-injection drug users are more susceptible to $\mathrm{HCV}$ infection than the general population (OR=6.82, 95\% CI: 1.93-24.11). Hagan et al. suggested that multiple interventions for drug users are likely to be more effective than single intervention (including behavioral intervention, opiates/alternative treatment, syringe exchange, syringe disinfection, etc.) $(\mathrm{OR}=0.25,95 \%$ CI: 0.07 to 0.83$)^{[17]}$.

\section{Heterosexual and homosexual sex}

Some controversies exist that sexual behavior also causes hepatitis C, especially the sexual intercourse of fixed spouse/ sexual partner. Although the methods of spread are similar, the sexual spread of HCV is less efficient than that of hepatitis $B$ virus and $\mathrm{HIV}$ virus, but the $\mathrm{HCV}$-infected persons and the prevalence of sexual behavior compose a large number of viral repositories, which cannot be ignored. Compared with fixed spouse/sexual partner, multiple sexual partner, male homosexual sex actor, $\mathrm{HCV}$-infected sexual partner, $\mathrm{HCV}$ and HIV co-infected sexual partner, and sexual partner of injection drug use increase the risk of hepatitis $\mathrm{C}$ infection. When the spouse/partner is in the acute phase of HCV infection, sexual spread may be more efficient; whether the gender difference between men and women affects hepatitis $\mathrm{C}$ infection is still unclear ${ }^{[18]}$. Terrault et al. conducted a follow-up survey on 500 hepatitis $\mathrm{C}$ antibody positive carriers and their 15 years' fixed heterosexual sexual partners and found that only 20 cases of them are hepatitis $\mathrm{C}$ antibody positive, of which 9 cases have the same genotype with their spouses; they also found that 190,000 times of sexual behavior can cause hepatitis $\mathrm{C}$ infection ${ }^{[19]}$. Wandeler $e t$ al. conducted a follow-up study and found that HCV incidence in IDU population with HIV infections decreases, but the $\mathrm{HCV}$ incidence in MSM population with HIV infection 
increases by 18 times. They also conducted a COX regression analysis and found that HCV incidence in MSM population is associated with interruption of condom use ( $\mathrm{HR}=2.09$, 95\%CI: 1.33-3.29), syphilis infection $(\mathrm{HR}=2.11,95 \% \mathrm{CI}$ : 1.39-3.20), and HCV seroconversion ${ }^{[20]}$.

\section{Mother-to-child transmission}

Mother-to-child transmission of hepatitis C is uncommon; before 1992, iatrogenic infection may be the main way for infants to be infected with $\mathrm{HCV}^{[21]}$. When maternal serum HCV RNA is negative, the possibility of neonatal infection with HCV is very little; when maternal serum HCV RNA is positive, the possibility of neonatal infection with $\mathrm{HCV}$ will be increased from $4 \%$ to $7 \%$. The neonatal infection is associated with perinatal infection, prolonged labor after the rupture of membranes $(\mathrm{OR}=9.3$, 95\% CI: 1.5-179.7), and intrauterine monitoring of embryo (e.g., amniocentesis) $(\mathrm{OR}=6.7,95 \% \mathrm{CI}: 1.1-35.9)^{[21]}$. Fewer copy number of viral load (below 105) is less likely to increase infection; more copy number of viral load (below 105 ) is likely to increase infection (higher than $10^{6} / \mathrm{mL}$ ), and concurrent HIV infection will even increase the risk of infection by threefold or fivefold ${ }^{[22]}$.

\section{Summaries}

Risk factors of hepatitis $\mathrm{C}$ infection vary from region to region in different countries. In developed countries, hepatitis $C$ infection is mainly caused by injection drug use and high-risk sexual behavior, whereas in developing countries, the infection is mainly caused by unsafe medical injection and contaminated blood and blood products. Many factors may be related to hepatitis $\mathrm{C}$ infection, including demographic characteristics (age, sex, ethnicity, marital status, and occupation, etc.), personal behavior and religious beliefs (tattoos, punches, hairdressing, sharing of toothbrushes, sharing of razors, circumcision and rituals, etc.), health care and cosmetology (oral treatment, tattoo, eyebrow embroidery, plastic surgery, acupuncture, scraping, and cupping, etc.), and socioeconomic conditions (income, local medical and health conditions). In China's public health services, hepatitis $C$ prevention and control work should focus on blood donation, blood transfusion, preoperative hepatitis $\mathrm{C}$ screening, safe injection of medical institutions and related clinics, reduction of injection drug use, and high-risk sexual behavior. The implementation of these measures also requires public health physicians, clinicians, and laboratory testing personnel to work together with other relevant third-party organizations to improve detection, monitoring, intervention, and treatment of hepatitis $\mathrm{C}$.

\section{Declarations}

\section{Acknowledgements}

No.

\section{Competing interests}

The authors declare that they have no competing interest.

\section{Authors' contributions}

$\mathrm{C}$ Meng and $\mathrm{N}$ Li made the literature analysis and wrote, discussed and revised the manuscript of this review. ZX Tong, HX Yan and SX Min critically analyzed and corrected the manuscript. All authors read and approved the final manuscript.

\section{References}

1 Lavanchy D. The global burden of hepatitis C. Liver Int, 2009, 29 Suppl 1: 74-81.

2 Ward JW. The epidemiology of chronic hepatitis C and one-timehepatitis C virus testing of persons born during 1945 to 1965 in the United States. Clin Liver Dis, 2013, 17 (1): 1-11.

3 Kim AY, Onofrey S, Church DR. An epidemiologic update on hepatitis C infection in persons living with or at risk of HIV infection. J Infect Dis, 2013, 207 Suppl 1: S1-S6.

4 Guan YH, Fan JX, Wang Z, et al. Made a serosurvey and analysis on risk factors of hepatitis C epidemic in Henan Province. Zhonghua Liu Xing Bing Xue Za Zhi, 2012, 33(7): 722-725.

5 Nguyen LH,Nguyen MH. Systematic review:Asian patients with chronic hepatitis C infection. Aliment Pharmacol Ther, 2013, 37(10): 921-936.

6 Spada E, Mele A, Mariano A, et al. Risk factors for and incidence of acute hepatitis $\mathrm{C}$ after the achievement of blood supply safety in Italy: results from the National surveillance system. J Med Virol, 2013, 85(3): 433-440.

7 Guerra J, Garenne M, Mohamed MK, et al. HCV burden of infection in Egypt:results from a nationwide survey. J Viral Hepat, 2012, 19(8): 560-567.

8 Guadagnino V, Stroffolini T, Caroleo B, et al. Hepatitis C virus infection in an endemic area of Southern Italy 14 years later: evidence for a vanishing infection. Dig Liver Dis, 2013, 45 (5): 403-407.

9 Zhang M, Fan J, Li H, et al. Alternative risk factors of HCV infection in a rural community in China. Epidemiol Infect, 2010, 138(7): 1032-1035.

10 Goyet S, Lerolle N, Fournier-Nicolle I, et al. Risk factors for hepatitis C transmission in HIV patients, hepacam study, ANRS 12267 Cambodia. AIDS Behav, 2014, 18(3): 495-504. 
11 Su Y, Norris JL, Zang C, et al. Incidence of hepatitis C virus infection in patients on hemodialysis: a systematic review and meta-analysis. Hemodial Int, 2013, 17(4): 532-541.

12 Jadoul M, Barril G. Hepatitis C in hemodialysis:epidemiology and prevention of hepatitis C virus transmission. Contrib Nephrol, 2012, 176: 35-41.

13 Nelson PK, Mathers BM, Cowie B, et al. Global epidemiology of hepatitis $\mathrm{B}$ and hepatitis $\mathrm{C}$ in People who inject drugs: results of systematic reviews. Lancet, 2011, 378(9791): 571-583.

14 Zhou YH, Yao ZH, Liu FL, et al. High prevalence of HIV, HCV, HBV and co-infection and associated risk factors among injecting drug users in Yunnan province, China. PLoS One, 2012, 7(8): e42937.

15 Amin-Esmaeili M, Rahimi-Movaghar A, Razaghi EM, et al. Factors correlated with hepatitis $\mathrm{C}$ and $\mathrm{B}$ virus infections among injecting drug users in Tehran, IR Iran. Hepat Mon, 2012, 12 (1): 23-31.

16 Kassaian N, Adibi P, Kafashaian A, et al. Hepatitis C virus and associated risk factors among prison inmates with history of drug injection in isfahan, Iran. Int J Prev Med, 2012, 3 (Suppl 1): 156-161.
17 Hagan H, Pouget ER, Des Jarlais DC. A systematic review and metaanalysis of interventions to prevent hepatitis $\mathrm{C}$ virus infection in People who inject drugs. J Infect Dis, 2011, 204(1): 74-83.

18 Indolfi G, Nesi A, Resti M. Intrafamilial transmission of hepatitis C virus. J Med Virol, 2013, 85(4): 608-614.

19 Terrault NA, Dodge JL, Murphy EL, et al. Sexual transmission of hepatitis $\mathrm{C}$ virus among monogamous heterosexual couples:the HCV partners study. Hepatology, 2013, 57(3): 881-889.

20 Wandeler G, Gsponer T, Bregenzer A, et al. Hepatitis C virus infections in the Swiss HIV cohort study: a rapidly evolving epidemic. Clin Infect Dis, 2012, 55(10): 1408-1416.

21 Le Campion A, Larouche A, Fauteux-Daniel S, et al. Pathogenesis of hepatitis C during pregnancy and childhood. Viruses, 2012, 4(12): 3531-3550.

22 Mast EE, Hwang LY, Seto DS, et al. Risk factors for perinatal transmission of hepatitis $\mathrm{C}$ virus (HCV) and the natural history of $\mathrm{HCV}$ infection acquired in infancy. J Infect Dis, 2005, 192(11): 1880-1889. 